\title{
Establishment of Evapotranspiration Model of Vegetation Communities in Xilin River Basin
}

\author{
Congming Cao ${ }^{1}$, Hongbo $\mathrm{Yu}^{1,2}$, Tao Guo ${ }^{1}$, Qiaofeng Zhang ${ }^{1,2}$ \\ ${ }^{1}$ College of Geography Science, Inner Mongolia Normal University, Huhhot 010022, China \\ ${ }^{2}$ Inner Mongolian Key Laboratory of Remote Sensing and Geography Information System, Huhhot \\ 010022, China
}

\section{锡林河流域植被群落蒸散模型的建立 \\ 曹䏲明 ${ }^{1}$, 于红博 ${ }^{1,2}$, 郭春 ${ }^{1}$, 张巧风 ${ }^{1,2}$ \\ ${ }^{1}$ 内蒙古师范大学 地理科学学院, 呼和浩特 010022 , 中国 \\ ${ }^{2}$ 内蒙古自治区遥感与地理信息系统重点实验室, 呼和浩特 010022 , 中国}

\section{Abstract}

Surface evapotranspiration is the process of moisture exchange in the atmosphere , biosphere and hydrosphere. Accurate estimation of evapotranspiration has important application value for regional water resources assessment, crop water requirement and production management, agricultural drought monitoring and ecological environmental issues.In this study, eight plots were selected in the upper, middle and lower reaches of the Xilin River Basin, including the main plant communities with severe degradation, slight degradation, and no degradation in the basin. The soil column weighing method was used to measure the daily evapotranspiration in each sample plot. Based on the meteorological, soil, and vegetation data measured over the same period, a mathematical relationship model between the evapotranspiration and meteorological factors, soil moisture, and community vegetation characteristics was established. The model is well-fitted and validated by randomly selected 20 groups of data. Within the allowable error range, the model meets the accuracy requirements and can be used for model estimation of vegetation
\end{abstract}

communities evapotranspiration in Xilin River Basin.

Keywords: evapotranspiration model; Xilin River Basin; soil column weighing method

摘要

地表蒸散是大气圈、生物圈和水圈进行水 分交换的过程, 精确估算蒸散量对区域水 资源评价、农作物需水量和生产管理、农 业旱情监测以及生态环境问题等方面都具 有十分重要的应用价值。本研究在锡林河 流域上、中、下游共选取了 8 个样地, 包 括该流域严重退化、轻度退化和未退化的 主要植物群落。每个样地采用土柱称重法 测定日蒸散量, 并根据实测的同期气象、 土壤、植被等数据, 建立了群落蒸散量与 气象因子、土壤水分、群落植被特点之间 的数学关系模型, 模型拟合度良好, 并用 随机选取的 20 组数据进行验证, 平均相对 误差为 $14.03 \%$, 小于 FAO P-M 模型联合作 物系数模拟的验证误差, 说明该模型符合 精度要求, 可以用于锡林河流域植被群落 蒸散量的模型估算。

关键词: 蒸散模型; 锡林河流域; 土柱称 重法

1. 引言

蒸散包括土壤蒸发和植被蒸腾, 是地 
面整体向大气输送水汽的过程 ${ }^{[1]}$ 。实际蒸散 在水循环过程中占降水总量的 $60 \%$, 在干 旱半干旱地区甚至更高 ${ }^{[2]}$, 同时可对流交换 $50 \%$ 的太阳辐射, 因此蒸散是土壤-植被-大 气系统水分和能量传输的决定性因素 ${ }^{[3]}$ 。实 际蒸散量的多少受气象因子、土壤水分、 植被覆盖状况等的共同影响 ${ }^{[4]}$, 实地测量需 要耗费大量的人力物力财力, 且具有尺度 限制, 构建模型便于估算大尺度上的蒸散 量。

现有的蒸散模型诸如水量平衡法、能 量平衡法等, 存在部分参数难以精准获取 造成模拟误差的问题 ${ }^{[5]}$ 。以辐射法为基础的 Priestley-Taylor 模型 ${ }^{[6]}$ 和曾在 1998 年被 FAO (Food and Agriculture Organization, 联 合国粮农组织) 推荐使用的 PenmanMonteith 方程 ${ }^{[18]}$ 因模拟精度良好被广泛使用, 但应用于半干早草原区的实际蒸散量计算 时, 还需考虑经过实践验证的修正系数 ${ }^{[7]}$ 。 同时考虑土壤蒸发和植被蒸腾的 Shuttleworth-Wallace 模型 ${ }^{[8]}$ 具有完善的理论 基础, 但模型计算参数较多 ${ }^{[9]}$, 部分参数如 冠层内部阻抗的推算较为复杂 ${ }^{[4]}$, 不易计算。 且上述模型多采用气象数据建立, 很少有 直接运用土壤水分因子和植被覆盖状况相 关参数计算的。因此, 建立锡林河流域植 被群落的蒸散模型十分必要。

本文通过土柱称重法 (即微型蒸渗仪 法) 测定锡林河流域不同植被群落的日蒸 散量, 分析蒸散量与环境因子和植被覆盖 状况之间的关系 ${ }^{[10]}$, 建立了锡林河流域植 被群落蒸散模型, 为估算该地区流域尺度 的蒸散量奠定基础。

\section{2. 研究区概况}

锡林河是内蒙古高原上的一条内陆河, 发源于赤峰市克什克腾旗, 流域 $\left(43^{\circ} 26^{\prime}-\right.$ $44^{\circ} 39^{\prime} \mathrm{N}, 115^{\circ} 32^{\prime}-117^{\circ} 12^{\prime} \mathrm{E}$ ) 总面积为 $9786 \mathrm{~km}^{2}$, 海拔 902-1505.6m, 属大陆性温 带半干旱气候, 夏季暖湿冬季冷干, 年降 水量在 250-400 mm 之间。流域内土壤类型 自东南向西北依次分布着黑钻土、暗栗钙 土和淡栗钙土 ${ }^{[11]}$ 。流域植被以草原 (典型 草原、草甸草原) 为主, 占比 $85 \%$ 以上, 上游为贝加尔针茅 (Stipa baicalensis) 草原
和线叶菊 (Filifolium sibiricum) 草原群落, 中游为羊草 (Leymus chinensis) 草原和大 针茅 (Stipa grandis) 草原群落, 下游为克 氏针茅 (Stipa krylovii) 草原和冷蒿 (Artemisia frigida) 草原群落 ${ }^{[12]}$ 。

近年来, 锡林河流域草原植被正在逐 步退化, 总体上从上游到下游退化程度逐 渐加剧, 浑善达克沙地沿河地区为重度退 化, 锡林浩特市以北的区域尤其是流域西 北部, 已经达到了极度退化; 流域中部以 中度退化为主; 轻度退化则均匀地分布于 整个流域 ${ }^{[13]}, 2000$ 年后草地退化趋势开始 减缓并有所恢复 ${ }^{[14]}$, 据本项目组成员于 2017 年植被生长季对该流域进行实地考察 发现, 大部分草地仍处于不同程度的退化 状态。

\section{3. 实验样地与研究方法}

\section{1 实验样地选取}

在锡林河流域上游白音锡勒牧场以南 选取了 2 个样地, 分别为轻度退化和严重退 化的草甸草原群落 (上游基本均为退化草 原); 在锡林河流域中游毛登牧场选取了 3 个样地, 分别为未退化和轻度退化的羊草 草原群落、轻度退化的大针茅草原群落; 在锡林河流域下游巴彦宝拉格苏木选取了 3 个样地, 分别为未退化的克氏针茅草原群 落 1 个、严重退化的克氏针茅草原群落 2 个。 整个流域共计 8 个样地, 每个样地所做工作 均为 3 次重复, 取平均值。

\section{2 研究方法}

采用土柱称重法测定日蒸散量。在样 地内选择植物生长均匀的地方, 用直径 $25.3 \mathrm{~cm}$, 深度 $25 \mathrm{~cm}$ 的铁桶, 在不破坏土壤 结构和植被的情况下, 完整放入同样体积 的圆形土柱, 再将土柱与地面平行埋于观 测地中, 模拟实际蒸散状况。每日 20: 00 进行一次称重, 根据土柱重量变化获得不 同群落的日蒸散量, 电子天平的灵敏度为 $1 \mathrm{~g}$ 。

用便携式温湿光记录仪, 获得空气温 度 $\left({ }^{\circ} \mathrm{C}\right)$ 、空气相对湿度 $(\%)$ 、光照强度 (Lux) 等气象数据。每日 6:00-20: 00 每 
隔 2 小时测量一次, 取平均值, 分别计为白 天的均温、平均相对湿度等 ${ }^{[15]}$; 日照时数、 $10 \mathrm{~m}$ 处风速等资料来源于国家气象科学数 据共享服务平台 (http://data.cma.cn/) 中国 地面国际交换站气候资料日值数据集。

用土壤墑情速测仪分别测定 $0-10 \mathrm{~cm}$ 、 $10-20 \mathrm{~cm} 、 20-30 \mathrm{~cm}$ 的土壤体积含水量 $(\%)$ ， 获得该样地的土壤水分数据。

在观测样地内取 $1 \mathrm{~m} \times 1 \mathrm{~m}$ 的样方, 植被 盖度 $(\%)$ 、叶干重 $(\mathrm{g})$ 等群落植被数据; 在 8 个样地中采集了 32 组不同植物叶片 (每组 3-5 片叶子), 用坐标纸计算叶面积, 将叶片在 $60^{\circ} \mathrm{C}$ 的烘箱中烘干称重, 以此建 立叶面积与叶干重之间的回归关系 ${ }^{[16]}$, 电 子天平的灵敏度为 $0.001 \mathrm{~g}$; 根据叶面积与 叶干重的回归关系, 通过样方内植物叶干 重, 计算出样方的叶面积指数 (\%)。

\section{3 数据处理}

于 2017 年 5-9 月植物生长期, 每月每 个样地进行 2-3 天的野外实验, 共获得 102 组数据, 随机选取 20 组数据同时用于模型 验证和对比, 使用 82 组数据构建植被群落 蒸散模型。

用 Excel 2010、SPSS 19.0 软件进行数 据处理与分析。

\section{4. 植被群落蒸散模型的建立}

\section{1 模型概述}

影响实际蒸散量变化的因素众多, 不 同因子之间也相互影响, 所以蒸散量的变 化成因十分复杂 ${ }^{[17]}$ 。因此, 本文选取土壤 含水量、平均气温、大气相对湿度、光照 强度、植被盖度以及叶面积指数 6 个环境因 子, 分析蒸散量与实测环境因子之间的相 关关系 (表 1 )。

结果显示, 蒸散量与上述 6 个因子之间 均为正相关关系, 其中土壤含水量、植被 盖度、叶面积指数、平均气温与蒸散量相 关性较大, 在置信度为 0.01 时显著相关; 大气平均相对湿度、光照强度等因子与蒸 散量的相关性较小。由于植被盖度与叶面 积指数的相关系数为 0.82 , 两个环境因子 之间相关性较大, 因此在建模过程中选取
与蒸散量相关性更高的植被盖度, 剔除叶 面积指数这一环境因子。

表 1 植被群落蒸散量与环境因子之间相关关系

环境土壤含 平均 相对 光照 植被 叶面积 因子 水量 气温湿度 强度 盖度 指数

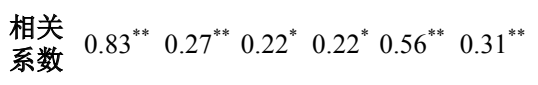

注: $* *$ 在 0.01 水平上显著相关, $*$ 在 0.05 水平 上显著相关。

分析实测环境因子与蒸散量的关系, 主要选取了土壤含水量、植被盖度、大气 温度、大气相对湿度等因子, 建立锡林河 流域群落蒸散模型如下:

$$
E T=0.14805 \frac{R_{n} \times \Delta \times T \times S C D \times w_{s}}{\Delta+\gamma}+0.392 \text { (1) }
$$

其中: $\mathrm{ET}$ 为日蒸散量, $\mathrm{mm} / \mathrm{day} ; \mathrm{R}_{\mathrm{n}}$ 为净 辐射, $\mathrm{MJ} /\left(\mathrm{m}^{2} \cdot\right.$ day $)$; $\mathrm{T}$ 为白天的均温, ${ }^{\circ} \mathrm{C}$; $\mathrm{SCD}$ 为盖度 (取值为 0-1 之间); $\mathrm{W}_{\mathrm{s}}$ 为土壤 体积含水量 (取值为 $0-1$ 之间); $\Delta$ 为饱和 水汽压与温度曲线斜率, $\mathrm{kPa} /{ }^{\circ} \mathrm{C} ; \gamma$ 为湿度 计常数, $\mathrm{kPa} /{ }^{\circ} \mathrm{C}$ 。

净辐射 $R_{n}$ 的计算公式[18]如下:

$$
R_{n}=R_{n s}-R_{n l}
$$

其中: $\mathrm{R}_{\mathrm{ns}}$ 为净太阳短波辐射, $M J /$ $\left(m^{2}\right.$.day ); $R_{n l}$ 为净地面长波辐射, $M J /$ $\left(\mathrm{m}^{2}\right.$.day)。净太阳短波辐射 $\mathrm{R}_{\mathrm{ns}}$ 由下式[18] 可得:

$$
\mathrm{R}_{\mathrm{ns}}=\left(0.25+0.5 \frac{\mathrm{n}}{\mathrm{N}}\right) \frac{1108.80}{\pi} \mathrm{G}_{\mathrm{sc}} * \mathrm{~d}_{\mathrm{r}} *
$$

$\left(\omega_{\mathrm{s}} \sin \varphi \sin \delta+\cos \varphi \cos \delta \sin \omega_{\mathrm{s}}\right)$

其中: $n$ 为实际日照时数, $h ; N$ 为理论最 大日照时数, $\mathrm{h} ; \mathrm{G}_{\mathrm{sc}}$ 为太阳常数, $0.082 \mathrm{MJ} /$ $\left(\mathrm{m}^{2} \cdot \mathrm{min}\right) ; \mathrm{d}_{\mathrm{r}}$ 为日地距离系数; $\omega_{\mathrm{s}}$ 为太阳 时角, 弧度; $\varphi$ 为观测样地的纬度, 弧度; $\delta$ 为太阳赤纬, 弧度。计算方式[18]如下:

$$
\begin{aligned}
& N=\frac{24}{\pi} \omega_{s} \\
& d_{r}=1+0.033 \cos \left(\frac{2 \pi}{365} J\right) \\
& \omega_{s}=\arccos (-\tan \varphi) \tan \delta
\end{aligned}
$$




$$
\delta=0.409 \sin \left(\frac{2 \pi}{365} J-1.39\right)
$$

其中: $\mathrm{J}$ 为年内日序; 其余参数定义如前。

净地面长波辐射 $\mathrm{R}_{\mathrm{nl}}$ 由下式[18]可得:

$$
R_{n l}=\sigma(T+273.16)^{4}(0.34-
$$

$\left.0.14 \sqrt{ } e_{a}\right) *\left(1.35 \times \frac{0.25+0.5 n / N}{0.75+2 \times 10^{-5}}-0.35\right)(8)$ 其中: $\sigma$ 为斯蒂芬 - 玻尔兹曼常数, $4.903 \times 10^{-9} \mathrm{MJ} /\left(\mathrm{k}^{4} \cdot \mathrm{m}^{2} \cdot \mathrm{day}\right) ; \mathrm{e}_{\mathrm{a}}$ 为实际水 汽压, $\mathrm{kPa}$; 其余参数定义如前。实际水汽 压 $e_{a}$ 的计算公式 $[18]$ 如下:

$$
e_{a}=e_{s} \times \frac{R H}{100}
$$

其中: $e_{s}$ 为饱和水汽压, $k P a$, 计算方式见 式 (11); RH 为白天的大气相对湿度, $\%$ 。 饱和水汽压 $e_{s}$ 与温度曲线斜率 $\Delta$ 的计算 公式[18]如下:

$$
\begin{gathered}
\Delta=\frac{4098 e_{S}}{(T+237.3)^{2}} \\
e_{s}=0.6108 \exp \left[\frac{17.27 T}{T+237.3}\right]
\end{gathered}
$$

式中参数定义如前。

湿度计常数 $\gamma$ 的计算公式[18]如下:

$$
\gamma=\frac{C_{p} P}{0.622 \lambda}=\frac{1.013 \times 10^{-3} P}{0.622 \lambda}=0.00163 \frac{P}{\lambda}
$$

其中: $C_{p}$ 为定压比热, $\mathrm{MJ} /\left(\mathrm{kg} \cdot{ }^{\circ} \mathrm{C}\right) ; \lambda$ 为 汽化潜热, $M J / \mathrm{kg} ; \mathrm{P}$ 为大气压, $\mathrm{kPa}$ 。汽 化潜热 $\lambda$ 和大气压 $\mathrm{P}$ 分别由下式[18]可得:

$$
\begin{aligned}
& \lambda=2.501-\left(2.361 \times 10^{-3}\right) T \\
& P=101.3\left(\frac{293-0.0065 Z}{293}\right)^{5.26}
\end{aligned}
$$

其中: $\mathrm{Z}$ 为海拔高度, $m$; 其余参数定义如 前。

\section{2 精度分析}

图 1 表示模型模拟值与实测日蒸散量值 的关系图, 判定系数 $R^{2}=0.7926$, 拟合优度 较高。

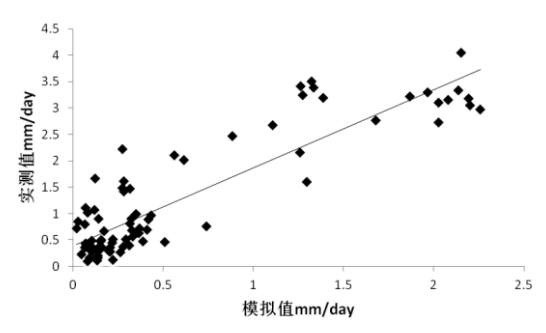

图 1 日蒸散量的模型模拟值与实测值对比

\section{3 模型验证}

将随机选取的 20 组验证值分别代入公 式 (1) 和利用 FAO 推荐的估算参考作物蒸 散量的 Penman-Montieth 模型 (简称 P-M 模 型), 计算模型模拟值与实测值之间的相对 误差 E (图 2)。

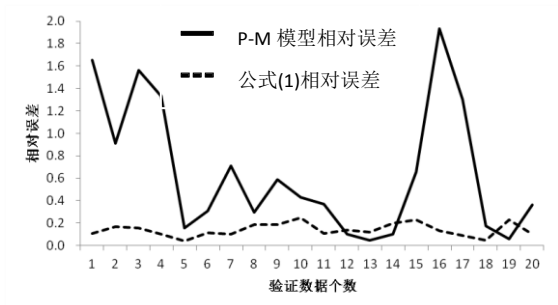

\section{图 2 日蒸散量模拟值与实测值相对误差}

利用加入作物系数的 P-M 模型计算实 际日蒸散量的公式 ${ }^{[18]}$ 如下:

$$
E T_{p}=k_{c} \frac{0.408 \Delta \times R_{n}+\gamma \frac{900}{T+273} u_{2\left(e_{s}-e_{a}\right)}}{\Delta+\gamma\left(1+0.34 u_{2}\right)}
$$

其中: $\mathrm{ET}_{\mathrm{p}}$ 为 $\mathrm{P}-\mathrm{M}$ 模型计算的实际日蒸散量, $\mathrm{mm} / \mathrm{day} ; u_{2}$ 为 $2 \mathrm{~m}$ 处的风速, $\mathrm{m} / \mathrm{s} ; \mathrm{T}$ 为 24 小时的日均温, ${ }^{\circ} \mathrm{C}$; $\mathrm{RH}$ 为 24 小时的大气 日平均相对湿度, $\% ; \mathrm{k}_{\mathrm{c}}$ 为作物系数 ${ }^{[19]}, 4-$ 5 月取值 0.8, 6-7 月为 $0.95,8-9$ 月取值 $0.85^{[18]}$; 其余参数定义及计算方法如前。

$2 \mathrm{~m}$ 处的风速 $\mathrm{u}_{2}$ 由下式 ${ }^{[18]}$ 可得:

$$
u_{2}=u_{10} \frac{4.87}{\ln (678-5.42)}
$$

其中: $\mathrm{u}_{10}$ 为 $10 \mathrm{~m}$ 处 24 小时的日平均风速, $\mathrm{m} / \mathrm{s}$ 。

相对误差的计算公式 ${ }^{[15]}$ 如下:

$$
E=\frac{|M-N|}{M}
$$


其中: $E$ 为相对误差; $M$ 为实测值, $\mathrm{mm} / \mathrm{day} ; \mathrm{N}$ 为模型模拟值, $\mathrm{mm} / \mathrm{day}$ 。

20 组数据的验证结果显示, 公式 (1) 的模拟值与实测值间的平均相对误差为 $14.03 \%$, FAO P-M 模型联合作物系数计算 的实际日蒸散量的平均相对误差为 $65.31 \%$ 。 FAO P-M 模型的相对误差较大, 这可能与 该模型主要通过气象因子建立, 且不适用 于锡林河流域蒸散的估算有关。公式 (1) 验证组的相对误差小于 $20 \%$, 误差较小, 表明综合考虑了土壤含水量与植被覆盖状 况的模型具有更高的模拟精度。

\section{5. 结论}

本研究通过测量土壤水分、气象、植 被等参数, 采用土柱称重法测定蒸散量, 利用实测数据建立了锡林河流域植被群落 的蒸散模型, 精度分析和模型验证结果显 示, 判定系数 $\mathrm{R}^{2}$ 在 0.79 以上, 相对误差为 $14.03 \%$, 在误差允许范围之内, 表明该模 型符合精度要求, 可靠性较好, 可以用于 锡林河流域植被群落蒸散量的模型估算。

\section{Acknowledgements}

This study was supported by National Natural Science Foundation of China (41661009), Natural Science Foundation of Inner Mongolia ( 2017MS0408) , and Higher school science and technology research projects of Inner Mongolia (NJZY17047).

\section{致谢}

本研究得到了国家自然科学基金项目 (41661009); 内蒙古自治区自然科学基金 项目（2017MS0408）; 内蒙古自治区高等 学校科研项目 (NJZY17047) 的资助。

通讯作者: 于红博, E-mail： yuboge2003@sohu.com。

\section{参考文献}

[1] 周倜,彭志晴, 辛晓洲, 李福根. 非均匀地 表蒸散遥感研究综述, 遥感学报, 20(2): 257-259, 2016.
[2] 刘绍民,孙中平, 李小文, 刘昌明.蒸散量 测定与估算方法的对比研究, 自然资源 学报,18 (2): 161-167, 2003.

[3] Jingjing Xiao, ZhiguoHuo, Dapeng Huang, FenfenGuo, Yan Jiang, Gaofeng Fan, E. Youhao, Y.U. Caixia. Meteorological Grading Indexes of Water-saving Irrigation for Corn, Journal of Risk Analysis and Crisis Response, 3(2): 95-100, 2013.

[4] 宋璐璐, 尹云鹤, 吴绍洪.蒸散发测定方法 研究进展, 地理科学进展,31(9): 11861195, 2012.

[5] Fisher J B, Whittaker R J, Malhi Y. ET come home: Potential evapotranspiration in geographical ecology, Global Ecology and Biogeography, 20(1): 1-18, 2011.

[6] Priestley C H B, Taylor R J. On the assessment of surface heat flux and evaporation using large scale parameters, Monthly Weather Review, 100(2): 81-92, 1972.

[7] Fisher J B, Malhi Y, Bonal D, et al. The land - atmosphere water flux in the tropics, Global Change Biology, 15(11): 2694-2714, 2009.

[8] Shuttleworth W J, Wallace J S. Evaporation from sparse crops-an energy combination theory, Q.J. Royal Meteorological Society, 111(469): 839855, 1985.

[9] $\mathrm{Hu} \mathrm{Z} \mathrm{M,} \mathrm{Yu} \mathrm{G} \mathrm{R,} \mathrm{Zhou} \mathrm{Y} \mathrm{L,} \mathrm{et} \mathrm{al.}$ Partitioning of evapotranspiration and its controls in four grassland ecosystems: Application of a two-source model, Agricultural and Forest Meteorology, 149(9): 1410-1420, 2009.

[10] 于红博,杨款,徐延达等.皇甫川流域单株 本氏针茅的蒸腾模型, 水土保持通 报,29(1): 78-82, 2009.

[11] 张雪峰,牛建明, 张庆等.内蒙古锡林河流 域草地生态系统土壤保持功能及其空 间分布,草业学报,24(1): 12-20, 2015. 
[12] Li B. S P Yong. Z H Li. The vegetation of Xilin river basin and its utilization, Research on Grassland Ecosystem, 3: 84$183,1988$.

[13] 姜晔,毕晓丽,黄建辉等.内蒙古锡林河流 域植被退化的格局及驱动力分析, 植物 生态学报,34(10): 1132-1141, 2010.

[14] 韩砚君, 牛建明, 张庆等.锡林河流域近 30 年草原植被格局动态及驱动力分析, 中国草地学报,36(2): 74-75, 2014.

[15] 于红博,杨劼, 徐延达等. 皇甫川流域中国 沙棘的树干液流量数学模型, 水土保持 研究, 16(1): 163-166, 2009.

[16] 于红博, 杨劼, 宋炳显. 黄土丘陵沟壑区植 物蒸腾和植被蒸散估算尺度转换模型 研究,水土保持研究,17(6): 90-94, 2010.

[17] 张明军,李瑞雪,贾文雄等.中国天山山区 潜在蒸发量的时空变化,地理学报,64(7): 798-806, 2009.

[18] Allen R G. Pereira L S. RAES D, et al. Crop evapotranspiration-guidelines for computing crop water requirements, FAO Irrigation and Drainage Paper 56, 1998.

[19] 于红博,包玉海, 张巧风等. 锡林河流域 蒸散量时空变化遥感监测, 水土保持研 究,21(6): 290-294, 2014. 